\title{
Energetic management in wild chimpanzees (Pan troglodytes verus) in Taï National Park, Côte d'Ivoire
}

\author{
Prince D. Valé ${ }^{1,2,3,4}$ (D) Jean-Claude K. Béné ${ }^{5} \cdot$ Antoine K. N'Guessan $^{5} \cdot$ Catherine Crockford $^{1,2} \cdot$ Tobias Deschner $^{1}$. \\ Inza Koné ${ }^{3,4} \cdot$ Cédric Girard-Buttoz ${ }^{1,2} \cdot$ Roman M. Wittig ${ }^{1,2}$
}

Received: 3 March 2020 / Revised: 8 November 2020 / Accepted: 12 November 2020 / Published online: 9 December 2020

(C) The Author(s) 2020

\begin{abstract}
Socioecological theories predict that, in mammals, feeding and mating competitions affect male and female energetic conditions differently but energetic studies investigating both sexes simultaneously are rare. We investigated the effect of socioecological factors on the energetic conditions of male and female western chimpanzees, a long-lived species with high degrees of male-male competition. We used behavioural data collected on one chimpanzee community in the Taï National Park over 12 months, phenological data and urinary c-peptide (UCP) measures, a marker of energy balance. We found a positive effect of food availability on UCP levels in both sexes. Dominance rank also affected chimpanzee UCP levels. High-ranking females had higher UCP levels than low-ranking ones but only in periods when no oestrus females were present in the community. In contrast, high-ranking males had higher UCP levels than low-ranking males in the presence of oestrus females but lower UCP levels in their absence. Our results suggest that oestrus female presence lessened the competitive advantages of high-ranking females in feeding competition and that low-ranking males bore higher energetic costs related to mating competition than high-ranking ones. Yet caution should apply in interpreting these results since the statistical model was only close to significance. High-ranking male and female chimpanzees spent significantly less energy. Furthermore, all chimpanzees significantly spent less time feeding and spent more energy when food availability was high. Finally, our behavioural measure of energy intake and expenditure did not correlate with UCP levels highlighting the value of non-invasive hormonal markers for field studies.
\end{abstract}

\section{Significance statement}

General socioecological theories hypothesize that the social grouping dynamic and energetics of females are highly influenced by food competition, whereas in males, competition for sexual partners is more influential for these factors. Recent studies in the non-invasive physiological assessment of energy balance in primates have begun to test the implied relationship between chimpanzee socioecology and individual energetic condition, with inconsistent results. However, only a few studies have investigated this relationship concurrently for both sexes. Here, using non-invasive measures of energy balance in wild western chimpanzees, we found that the energetics of both males and females are related to ecological factors, such as food availability. However, female energy balance appears also to be related to increased male mating competition, as this can result in increased aggression directed from males to females, with apparent energetic costs for females.

Cédric Girard-Buttoz and Roman M. Wittig jioint senior authorship.

Communicated by D. P. Watts

Prince D. Valé

valeprince15@yahoo.fr

Roman M. Wittig

wittig@eva.mpg.de

1 Max Planck Institute for Evolutionary Anthropology, Leipzig, Germany

2 Taï Chimpanzee Project, Centre Suisse de Recherches Scientifiques, Abidjan, Côte d'Ivoire
3 Centre Suisse de Recherches Scientifiques en Côte d'Ivoire, Abidjan, Côte d'Ivoire

4 Unité de Formation et de Recherche Biosciences, Université Félix Houphouët Boigny, Abidjan, Côte d'Ivoire

5 Unité de Formation et de Recherche Environnement, Université Jean Lourougnon Guédé, Daloa, Côte d'Ivoire 
Keywords Energy management $\cdot$ Food availability $\cdot$ C-peptide $\cdot$ Socioecological model $\cdot$ Feeding competition

\section{Introduction}

Energetic management, i.e. balancing energy intake and expenditure to maintain a positive energy balance, is a key determinant of animal reproductive success and survival (Hobbs 1989; Bosaeus et al. 2002; Stubbs and Tolkamp 2006). Most wild animals are subject to seasonal variation in food availability and reproductive opportunities which lead to variation in their energy balance (Tsuji et al. 2008; Emery Thompson et al. 2009). In non-human primates (hereafter "primates"), individuals face an additional challenge which is the high energy demand of their exceptionally large brain (Charnov and Berrigan 1993; Isler and van Schaik 2009). Thus, group-living primates have evolved specific behavioural and social adaptions to fulfil their energetic needs and adjust them to constraints such as seasonal variation in food abundance and mating competition (Zhang and Wang 2007; Tsuji et al. 2008; Emery Thompson et al. 2009; Wessling et al. 2018a).

Primates exhibit a wide variety of social organization ranging from solitary to large cohesive multi-male multi-female groups (Mitani et al. 2012). To better understand this variety and the social dynamics within groups, the socioecological model, linking food distribution and abundance to primate social dynamics, was developed in the 1980s (Wrangham 1980; van Schaik 1989). This model states that the distribution of food in space and time primarily affects female aggregation and feeding competition among females whereas males are primarily impacted by the spatio-temporal distribution of females and male-male competition for access to mates (Steenbeek and Sterck 1997; Kappeler 2000; Koenig 2002). The model does not claim that mating competition does not impact female sociality or that males do not compete over food but highlights a sex difference in the magnitude of both effects for each sex. In turn, female energy balance should be more sensitive to variation in ecological factors than males whereas male energy balance should be primarily impacted by the degree of mating competition in the group. Socioecological theories further hypothesise that female gregariousness evolved as a strategy to respond to between-group feeding competition and predation pressure (Wrangham 1980; van Schaik 1989). However, females are limited in their energetic acquisition by withingroup feeding competition (van Schaik 1989; Barton and Whiten 1993; Saito 1996; Wittig and Boesch 2003; Murray et al. 2006). This effect is expected to be unequal across conspecifics living in the same community since the high-ranking ones can easily monopolize access to food resources (Greengrass 2005; Pusey et al. 2005; Kahlenberg et al. 2008; Nurmi et al. 2018). Accordingly, high-ranking females are expected to acquire more energy and have higher energy intake, producing a more positive energy balance than low-ranking females (Ellis 1995; Sterck et al. 1997). In contrast, the effect of dominance rank on energy intake in males is expected to be lower than in females, and rank effects on male energy balance are expected mainly in periods of high mating competition where high-ranking males compete to access fertile females (Muller and Wrangham 2004).

Nevertheless, there is a lack of studies directly assessing the impact of feeding competition and mating competition on energetic condition in both sexes within the same study and using a single analysis. More generally, and because of the foundational assumption of the socioecological theories, studies analyzing the impact of food availability on energetic condition often focus on females (Emery Thompson et al. 2012), and studies analyzing the impact of mating competition (measured by the presence of fertile females, the rate of male-male aggression and/or the degree of female monopolization) on energetic conditions focus on males (Emery Thompson et al. 2009; Georgiev 2012; Girard-Buttoz et al. 2014a).

To fill this gap, we quantify how socioecological factors drive male and female western chimpanzee's (Pan troglodytes verus) energetic condition to better understand the energetic management strategies of this subspecies, characterized by a lower occurrence of female coercion by males than eastern chimpanzees (Pan troglodytes schweinfurthii) (Stumpf and Boesch 2005; Boesch et al. 2008). In chimpanzees, studies directly linking variation in food availability and mating competition to the energetic condition of males and females are limited, and these studies led to conflicting results. In western chimpanzees, the presence of oestrus females overruled ecological factors, and food availability did not affect grouping patterns when these females were present (Anderson et al. 2002). In eastern chimpanzees, males in large parties reduced their feeding time in the presence of oestrus females, and there was no effect of mean daily party size on male feeding time (Georgiev et al. 2014).

Furthermore, these studies rely mostly on behavioural measures of feeding time or food intake which can lead to imprecise estimation of energy gain and provide no information on energy balance (Emery Thompson 2017). To circumvent this limitation, researchers have developed and validated the use of physiological markers of wild primate energetic conditions such as c-peptide, a peptide produced on an equimolar ratio with insulin, a hormone involved in compartmentalizing and storing of energy (Steiner and Oyer 1967; Rubenstein et al. 1969; Melani et al. 1970). Urinary c-peptide (UCP) has been validated as a marker of energetic condition in several monkey and ape species, including chimpanzees (Deschner et al. 2008; Emery Thompson and Knott 2008; Emery Thompson et al. 2009; Girard-Buttoz et al. 2011). These studies highlight the 
validity of c-peptide as a reliable marker of energy balance (Emery Thompson 2017) since UCP levels covary with energy intake (Girard-Buttoz et al. 2011), body condition (i.e. body mass and body fatness, Girard-Buttoz et al. 2011) and energy expenditure since in wild macaques UCP levels tend to be negatively correlated to the height climbed (Girard-Buttoz et al. 2014a). High levels of UCP indicate positive energy balance and low levels indicate negative energy balance. Recently, investigations of chimpanzee socioecology using UCP revealed some contrasting patterns across and within populations. High-ranking males who compete the most intensely for access to and monopolization of fertile females had lower UCP levels than low-ranking males (Emery Thompson et al. 2009; Georgiev 2012). Males occupying a more productive habitat had higher UCP levels than their neighbouring community in a less productive area (Emery Thompson et al. 2009). Finally, female eastern chimpanzees had lower UCP levels when associating with more males than when associating with more females (Emery Thompson et al. 2014). These studies provide some contrast to a dichotomic view of socioecological theory by showing that (1) males can also be strongly impacted by food availability and (2) malefemale competition might affect female energetic condition more than female-female competition.

The specific aim of our study was to understand the effects of feeding competition, dominance rank and mating competition on the energy balance of both males and females. We derived hypothesis and predictions from socioecological theories (summarized in Table 1). We hypothesized that females should be more affected than males in their energetic condition by food availability and that social factors (dominance rank and presence of oestrus females) should have different effects on males' and females' energetic conditions. We predicted that high-ranking females will have a more positive energy balance (higher UCP levels) than low-ranking ones and that this effect will be independent of the presence or absence of oestrus females in the party. In males, we predict that high-ranking individuals will have in general higher UCP levels than low-ranking males since they have priority of access to high-quality food (Whitten 1983; Isbell et al. 1999).
However, in the presence of oestrus females, the higher ranking individuals, which are the ones which invest more in mating competition (Muller and Wrangham 2004), will have lower UCP levels than low-ranking individuals since mating competition and female monopolization is costly for males (Alberts et al. 1996; Georgiev 2012; Girard-Buttoz et al. $2014 a$, b). We studied one community of chimpanzees over 12 months in Taï National Park using a combination of phenological measures to assess food availability, behavioural observations to assess energy intake and energy spent on activities and UCP levels as a marker of energy balance.

\section{Material and methods}

\section{Study site and subjects}

We conducted the study from July 2017 to June 2018 at the Taï Chimpanzee Project (TCP) $\left[5^{\circ} 45^{\prime} \mathrm{N}, 7^{\circ} 07^{\prime} \mathrm{W}\right.$ (Wittig 2018)] in the Taï National Park Cote d'Ivoire. We observed North group, which consisted of 21 chimpanzees with 3 adult males, 1 subadult male, 7 adult females, 3 juveniles and 7 infants in July 2017. Males of 15 years and females of 13 years and older were considered adults, males between 12 and 15 were considered subadults (similar to Watts and Pusey 2002; Wroblewski et al. 2009).

\section{Behavioural observations}

PDV conducted all-day focal animal sampling (Altmann 1974) on all adult and subadult males $(N=4)$ and females $(N=7)$ of the community with an average observation time per individual of $149.4 \mathrm{~h}$ (range: 130.8-167 h), resulting in 1643 focal observation hours (see supplementary Table S1). It was not possible to record data blind because our study involved focal animals in the field.

During focal follows, PDV recorded the focal activities continuously and social interaction using Cyber Tracker software (https://www.cybertracker.org/). We considered the following activities divided into (1) activities providing

Table 1 Predictions for our study derived from the socioecological model and summary of the outcomes of our analyses

\begin{tabular}{ll}
\hline Hypotheses & Predictions \\
\hline $\begin{array}{l}\text { Ecological factors influence energy } \\
\text { condition differently in males and females }\end{array}$ & $\begin{array}{c}\text { High food availability is associated to positive energy } \\
\text { balance with a stronger effect in females than males }\end{array}$ \\
$\begin{array}{l}\text { Social factors have different effects on males } \\
\text { and females energy condition }\end{array}$ & $\begin{array}{l}\text { 1. In females, higher dominance status is associated with } \\
\text { higher energy balance, regardless of the degree of mating competition }\end{array}$ \\
$\begin{array}{l}\text { 2. In males, higher dominance status is associated with higher } \\
\text { energy balance in the absence of mating competition and lower } \\
\text { energy balance in the presence of oestrus females }\end{array}$ \\
\hline
\end{tabular}


energy: feeding and (2) activities leading to energy expenditure: travelling, climbing, aggressing, resting, grooming, drumming and playing (for detailed definitions of the activity states and behaviour, see Table 2). During each feeding bout, PDV recorded the duration, the type (i.e. plants or meat and for plants, the part consumed such as leaves, fruit and flowers) and species name of the consumed food and the number of food items ingested. When the focal animal was on the ground, PDV counted each food item ingested during the entire feeding bout. When the chimpanzees consumed honey, ant, larvae, small leaves and flowers, PDV counted the number of handfuls ingested. When the focal chimpanzee was in a tree or visibility was reduced on the ground, the total number of items ingested was estimated based on extrapolation derived from counts of the number of food items ingested during 2 min every $10 \mathrm{~min}$. PDV made sure to cover all periods of the feeding bouts (beginning, middle and end). For large fruits, PDV estimated visually the weight of the whole fruit and the proportion obtained by the focal individual and for meat, he also visually estimated the weight of the prey and the proportion of meat obtained by the focal. While the focal was cracking nuts, PDV counted, when possible, the number of hits used to open each nut to calculate the energy spent for cracking nuts (see below). PDV collected (from the same individual food source, i.e. the same tree) and weighed food items to later estimate the quantity of food ingested by the chimpanzees. During every focal day, using the self-recording function of a GPS (Garmin GPSMAP 64s), PDV recorded the GPS track$\log$ of the focal individual and determined later the daily travel distance and velocity. We set the GPS to record location at a time interval automatically adjusted to the focal individual locomotion (i.e. points were recorded more frequently when the individual was travelling and less frequently when the individual was resting). Despite this setting, the GPS sometimes recorded multiple positions while the individual was immobile due to GPS position error. In order to smooth the track-log and delete errors, we cleaned and smoothed the tracks by removing consecutive positions recorded continuously at the same location using an algorithm developed by Janmaat et al. (2013). While travelling, PDV recorded if the focal was carrying an infant or not. He also continuously recorded changes in vertical locomotion in trees or other structures to estimate the daily climbing height of focal individuals. We considered 6 vertical strata adapted from Buzzard (2006): 0 = ground, $1=1-5 \mathrm{~m}, 2=6-10 \mathrm{~m}, 3=11-20 \mathrm{~m} ; 4=21-30 \mathrm{~m}$ and $5=>30 \mathrm{~m}$.

Since the presence of oestrus females can influence the dynamics of the community, including the dynamics of feeding competition (Muller et al. 2006; Sobolewski et al. 2013; Georgiev et al. 2014), PDV and experienced field assistants recorded, each day, the identity of the oestrus females in the community. Chimpanzees live in societies with a high degree of fission-fusion dynamics so that the party composition may change throughout the day depending on social and ecological events (Wrangham et al. 1996). Since community size can affect energy intake in chimpanzees through foraging efficiency (Isabirye-Basuta 1988), PDV recorded variation in the party composition continuously throughout the day when changes occurred to control for the potential effect of party size on chimpanzee energy balance.

\section{Estimation of energy intake}

We determined energy intake based on the rate of food items ingested by the daily focal individual. In total, PDV recorded 613 feeding focal hours comprising 3635 different feeding bouts. PDV was able to count the number of food item consumed by the focal individual during 2139 out of those 3635 bouts. We calculated an estimated food intake rate for each food species using the counts of the number of food items ingested. We then extrapolated the feeding rate to feeding time of each feeding bout where the target was in sight and feeding on an identified food item but its mouth was not visible such that PDV could not count the eaten items (i.e. during 1496

Table 2 Definition of the activity states and behaviours

\begin{tabular}{|c|c|c|}
\hline Behaviour & Description & Energetic function \\
\hline Feeding & $\begin{array}{l}\text { Effective consumption of food, chewing and manipulating food item (foraging which did not } \\
\text { result in food consumption was not included) }\end{array}$ & Energy intake \\
\hline Resting & Sitting or lying without being engaged in any other activity or any social interaction & Energy expenditure* \\
\hline Grooming & Sitting or lying, cleaning of skin or hair of self or other individuals & Energy expenditure* \\
\hline Travelling & Walking or running on the ground & Energy expenditure \\
\hline Climbing & Vertical or horizontal locomotion within a tree or across trees & Energy expenditure \\
\hline Aggression & $\begin{array}{l}\text { Contact aggression (attacks; e.g. bites, hits), non-contact aggression (e.g. chases, charges and } \\
\text { displays), threats (e.g. arm waves) and non-directed displays }\end{array}$ & Energy expenditure \\
\hline Drumming & Hit or kick tree trunks especially those with buttresses and usually preceded by a display & Energy expenditure \\
\hline Playing & Solo or social play & Energy expenditure \\
\hline
\end{tabular}

*Resting and grooming as well as feeding led to energy expenditure in the form of basal metabolic rate 
bouts). Based on a coefficient of dry weight computed in a previous study on the same chimpanzee population (N'Guessan et al. 2009), we assessed the dry weight of each food item from the fresh weight we measured in the field. For each food species, PDV collected and weighed several items and calculated an average weight per item for each species. Then, we calculated the total daily energy intake of the focal individual using the nutritional value of each food item as measured by N'Guessan et al. (2009) (see Supplementary Table S2) and by applying the following formula.

$\mathrm{DE}_{\text {int }}=\sum_{f=1}^{n}\left[N_{\mathrm{f}} \times \mathrm{DW}_{\mathrm{f}} \times\left(4 \times \% \mathrm{CP}_{\mathrm{f}}+4 \times \% \mathrm{TNC}_{\mathrm{f}}+9 \times \% \mathrm{~L}_{\mathrm{f}}+1.6 \times \% \mathrm{NDF}_{\mathrm{f}}\right)\right]$

DEint the total daily energy intake

$N_{\mathrm{f}} \quad$ the number of fruit $\mathrm{f}$ consumed in each feeding bout

$\mathrm{DW}_{\mathrm{f}}$ dry weight of one food item $\mathrm{f}$ consumed in each feeding bout

For a fruit $\mathrm{f}$, we have the following: $\mathrm{CP}=$ crude protein; $\mathrm{TNC}=$ total non-structural carbohydrates; $\mathrm{L}=$ lipid; $\mathrm{NDF}=$ neutral detergent fibre.

The details of average daily energy intake estimated for males and females and of food availability each month are shown in Table S3.

\section{Estimation of energy spent on activities}

In our study, the energy expenditure only focused on estimating the energy spent on activities. We calculated the daily energy spent on activities (DEA $\mathrm{exp}_{\text {e }}$ ) considering the energetic cost for resting metabolic rate (RMR) which is the amount of energy used for maintaining basal metabolic rate (BMR) during resting time and we added the energy expenditure of travelling (Et); climbing (Ec); nut cracking (En); eating (Ee) and social activities (Es). Since we do not know the exact weight of our study chimpanzees and since this information cannot be obtained non-invasively, we used a constant body mass for all the males of $46.3 \mathrm{~kg}$ which is the average body mass of a male western chimpanzee (Smith and Jungers 1997). Likewise, we assigned a body mass of $41.6 \mathrm{~kg}$ to each female which corresponds to the average body mass of a female western chimpanzee (Smith and Jungers 1997). The cost of each activity is calculated as a percentage of BMR (see below). BMR is estimated to be the same across all the study males and across all the study females. However, the equation below captures individual variation in daily energy spent on activities since it relates to the activity budget of each focal individual.

$\mathrm{DEA} \exp =\mathrm{RMR}+\mathrm{Et}+\mathrm{Ec}+\mathrm{En}+\mathrm{Ee}+\mathrm{Es}$
The averages daily energy spent on activities each month per sex are presented in the Supplementary material (Table S3).

\section{Basal metabolic rate and resting metabolic rate}

We estimated the BMR from a formula developed for chimpanzees by Pontzer et al. (2016). We referred to the relation between the RMR and BMR developed for orangutans (Pontzer et al. 2010, 2016) and we use the formula of chimpanzee BMR (Pontzer et al. 2016) to estimate the RMR of chimpanzees. We estimate BMR and RMR from the following formula where $M$ is the body mass of the individual in kilogram:

$$
\begin{gathered}
\operatorname{BMR}(\mathrm{kcal} / \text { day })=100.17 \times M^{0.65} \\
\operatorname{RMR}(\mathrm{kcal} / \text { day })=\mathrm{BMR} / 0.8
\end{gathered}
$$

\section{Energy expenditure for travelling (Et)}

We estimated the travel energy expenditure using the formula implemented by Pontzer et al. (2014) which posits that a chimpanzee travelling with a velocity $v$ consumes a volume of oxygen $\left(\mathrm{VO}_{2}\right)$ where:

$\mathrm{VO}_{2}=0.22 \times v+0.06 \mathrm{ml} \mathrm{kg}^{-1} \mathrm{~s}^{-1}$

We converted the volume of oxygen as 11 of $\mathrm{O}_{2}=4.8 \mathrm{kcal}$ following Schmidt-Nielsen (1997). Then, we obtained the travelling energy expenditure using the following formula:

$\mathrm{Et}=\mathrm{VO}_{2} \times 10^{-3} \times 4.8 \times M \mathrm{kcal} \mathrm{s}^{-1}$

When females were carrying an infant while travelling, we adjusted the cost of locomotion for that female by taking into account the additional load, following the approach by Pontzer and Wrangham (2004). Carrying an infant increases the percentage of energy spent on travelling proportionally to the mass of the load (Taylor et al. 1980). For instance, if a mother is moving while carrying an infant weighing $20 \%$ of the mother's body mass, it will spend $20 \%$ more oxygen than without the infant load (see Taylor et al. (1980) and Altmann and Samuels (1992) for details). Based on the body mass versus age curves obtained in eastern chimpanzees by Pusey (1990) and Pusey et al. (2005), we estimated the body mass of every carried infant in our study community using the following formula: Mass $_{\text {infant }}(\mathrm{kg})=2 *$ infant age (years).

\section{Energy expenditure for climbing (Ec)}

To determine the energy spent on climbing, we used the estimation implemented by Hanna et al. (2008) giving the following formula where $h$ is the height climbed and $M$ is the body mass: 
Ec $(\mathrm{kcal})=119.8 \times 10^{-3} \times 0.239 \times M \times h$

\section{Energy expenditure for nut cracking (Ec)}

By counting the number of hits used to open a nut during cracking sessions, we calculated a mean number of hits required to open one nut per individual and per nut species. We then extrapolated this mean across the entire cracking session. Günther and Boesch (1993) calculated the energetic cost of nut cracking in chimpanzees and found that chimpanzees use an amount of $0.04 \mathrm{kcal}$ per hit to crack a nut of Coula edulis. Following Günther and Boesch (1993), we evaluated the energy spent on nut cracking by multiplying the number of hits necessary to crack a nut by the energy spent on one hit.

\section{Energy expenditure for eating (Ee) and social activi- ties (Es)}

We estimated the energy used for eating and other activities with a formula of Leonard and Robertson (1997) who stated that for an activity performed during a time $t$, a coefficient $D$ can be used to estimate the energy spent. The coefficient $D$ varies with the activities: $D_{\text {eating }}=1.38$ and $D_{\text {social }}=2.35$. Thus:

$\mathrm{E} a=(\mathrm{D} a \times \mathrm{BMR} \times t) \times 24^{-1} \mathrm{kcal}$

\section{Assessment of food availability}

An experienced field assistant collected phenological data on 944 fruit trees belonging to 82 species frequently eaten by the chimpanzees using the same methods with N'Guessan et al. (2009). We thus estimated the food availability index $\mathrm{FA}_{\mathrm{m}}$, for each month " $\mathrm{m}$ " with the following formula from Anderson et al. (2002):

$\mathrm{FA}_{\mathrm{m}}=\sum_{k=1}^{n} D_{k} B_{k} P_{k m}$

$D_{k} \quad$ density of plant species $k$ within the study area.

$B_{k} \quad$ mean basal area (measured by trunk diameter at breast height) of species $k$ within the study area.

$P_{k m} \quad$ percentage of trees of species $k$ with mature fruits within the study area in a month.

\section{Assessment of dominance rank}

We calculated the dominance hierarchy using a modified version of the Elo-rating method (Neumann et al. 2011) developed by Foerster et al. (2016). We used the occurrence of unidirectional submissive pant-grunt vocalization (given by the lower ranking of the two individuals towards the higher ranking, Bygott 1979) to establish chimpanzee dominance ranks. We used all of the long-term data available from the Taï chimpanzee project consistently collected ad libitum by several field assistants, students and researchers since 2016. We calculated male and female Elo-rating scores separately and combined them in a single dominance hierarchy (see details in Mielke et al. (2017)), since all males are dominant over all females in the Taï chimpanzees (Gomes et al. 2009). We standardized all Elo-rating scores between 0 and 1 with 1 being the highest ranking individual and 0 the lowest ranking, on a daily basis. We then extracted the Elo-rating score of each individual on the focal observation day considered.

\section{Urine sample collection and analyses}

In addition to the behavioural data, PDV collected urine samples from the focal individual (one in the early morning and one in the late afternoon). We analyzed 175 samples for this study. PDV pipetted the urine directly from leaves or the ground into a 2-ml cryotubes. We made sure that the urine was not contaminated with faeces since contamination with faeces can severely alter urinary c-peptide measures (Higham et al. 2011). After collection, PDV placed the samples in a thermos cooler and froze the samples in liquid nitrogen within $12 \mathrm{~h}$ of collection at the research camp. We transported samples frozen on dry ice to the Laboratory of Endocrinology at the Max Planck Institute for Evolutionary Anthropology in Leipzig, Germany. In the laboratory, we thawed frozen urine samples at room temperature. After shaking for $10 \mathrm{~s}$ (VX2500 Multi-tube Vortexer), we then centrifuged the samples for $5 \mathrm{~min}$ at $4400 \mathrm{~g}$ (Multifuge Heraeus). We analyzed urine samples for c-peptide levels using C-Pep-EASIA KAP0401, which is a commercially available solid-phase enzyme-amplified sensitivity immunoassay kit from DIAsource, designed to measure C-peptide in human serum and already used in wild great apes (Surbeck et al. 2015; Wessling et al. 2018b). We added $100 \mu \mathrm{l}$ of pure urine in duplicates into the wells and followed assay instructions. Intra- and inter-assay coefficients of variation of low- and high-value quality controls were $9.4 \%$ and $7.4 \%(N=5)$ and $9.1 \%$ and $7.9 \%(N=9)$, respectively. Samples were diluted and re-measured if their measured values did not fall into the linear range of the assay and simply re-measured if the two duplicate measures differed by more than $10 \%$. C-peptide values were corrected according to creatinine content and are expressed in $\mathrm{ng} / \mathrm{mg}$ creatinine.

\section{Statistical analyses}

We investigated the socioecological factors affecting chimpanzee overall energy balance and the different components of energy balance (i.e. energy intake, feeding time and energy 
spent on activities) using four different linear mixed models (LMMs). The structure of all the LMMs ran for this study is summarized in Table 3. In Model 1, we used UCP levels as the response variable. Each urine sample constituted a data point $(N=175)$. We ran additional models to assess which components of the energy balance were impacted by the socioecological factors that we tested. We used the total daily energy intake (Model 2a), the percentage of observation time spent feeding (Model 2b) and the total daily energy spent on activities (Model 3) as responses in three separate LMMs. For Models 2a, 2b and 3, each data point was an observation day $(N=158$ days) and the response variable was assessed for each data point each day.

In all models, we tested the effect of four predictor variables: monthly food availability, sex, dominance rank and presence of oestrus females in the party (a proxy for the degree of mating competition) on the response. We assessed for each observation day whether at least one maximally swollen female was present in the party with the focal individual. We incorporated males and females within the same models to be able to include interactions between sex and our test predictors, and used the significance of such interactions to assess whether certain predictors have a stronger relationship to the energetic measures in one sex as compared to the other. We added an interaction between food availability and sex since we predicted that the energetics of females should be more influenced by food availability than males (Clutton-Brock and Harvey 1978; Sterck et al. 1997). We also incorporated a three-way interaction between rank, sex and presence of oestrus females into each of the four LMMs because we expected that the relationship between rank, mating competition and energetic conditions would differ for males and females since females are expected to compete more intensely over food than males while males are expected to allocate more energy to mating competition than females (Trivers 1972; Emlen and Oring 1977; Kappeler 2000).
In all models, we also added the average daily party size around the focal as a control variable. In addition, in Model 1, we added the time of sample collection to account for diurnal variation in UCP levels (Georgiev 2012). In Models 2a and 3, we also added an offset term for the observation time (in hours) to practically model energy intake and energy spent on activities per hour of observation (considering that the longer the individuals are observed each day, the more energy intake and energy spent on activities will be recorded).

In addition to these four models, we wanted to test directly the relationship between our measures of energy intake and energy spent on activities and UCP levels (a measure of energy balance) to assess indirectly the potential error pertaining to behavioural assessment of energetic parameters. We ran a fifth LMM (Model 4) (Table 3). We considered all urine samples ( $N=175$ samples) corresponding to the days ( $N=98$ days) when energy intake and energy spent on activities were measured. In all five LMMs, we incorporated individual ID as a random factor to avoid pseudoreplication arising from collecting several data points per individual.

We ran all the five LMMs (Baayen 2008) with a Gaussian error structure and identity link (McCullagh and Nelder 1989) in R software (version 3.5.3; R Development Core Team 2016) using the package "Ime4" (Bates et al. 2015). For all models, we included the maximal random slope structure between each fixed predictor (test and control) and each random effect (Baayen et al. 2008; Barr et al. 2013). In each model, we tested for the overall significance of the test predictors by comparing the full model to a null model comprising all control predictors, all the random effects and random slopes but without the test predictors. We tested each full model against its corresponding null model using a likelihood ratio test (LRT, Dobson 2002). We then assessed the significance of each predictor variable using an LRT between the full model and a reduced model comprising all the variables except the one to evaluate. This process was repeated across all variables

Table 3 Structure of the five LMMs used in this study

\begin{tabular}{|c|c|c|c|c|}
\hline Response & Predictors & Interactions & Control predictors & Random factor \\
\hline $\begin{array}{l}\text { Model } 1 . \\
\text { UCP levels }\end{array}$ & - Sex & - Food availability*sex & - Party size & Individual ID \\
\hline $\begin{array}{l}\text { Model } 2 \mathrm{a} . \\
\text { Energy intake } \\
\text { Model } 2 \mathrm{~b} . \\
\text { Feeding time } \\
\text { Model } 3 \text {. } \\
\text { Energy spent on activities }\end{array}$ & $\begin{array}{l}\text { - Food availability } \\
\text { - Dominance rank } \\
\text { - Presence of oestrus females }\end{array}$ & $\begin{array}{l}\text { - Dominance rank*sex*presence } \\
\text { of oestrus females }\end{array}$ & $\begin{array}{l}\text {-Time of sample collection } \\
\text { (only in Models } 1 \text { and } 4 \text { ) } \\
\text { - Observation time (as an offset term, } \\
\text { only in Models 2a and 3) }\end{array}$ & \\
\hline $\begin{array}{l}\text { Model } 4 . \\
\text { UCP levels }\end{array}$ & $\begin{array}{l}\text { - Energy intake } \\
\text { - Energy spent on activities }\end{array}$ & & & \\
\hline
\end{tabular}

In each model, we added food availability, party size, presence of oestrus female and time of sample collection (only in Models 1 and 4) within individual ID as random slopes

The model structure presented here is one of the full models (i.e. before removing the non-significant interactions). The model structure after removing the non-significant interactions (final models) can be found in Table 4 with the results of each model 
using the drop1 function. If the LRT revealed that one interaction had a $P$ value $>0.05$, we reran the model without this interaction and reassessed the significance of all the predictors.

We checked the model assumptions and verified that for all three models the residuals were normally distributed. We confirmed model stability by removing one level of each random effect at a time and recalculating the estimates of the different predictors which revealed comparable estimates to the original models. Finally, we tested for collinearity issues between the predictor variables using the function vif (variance inflation factor) from the package "car" (Fox and Weisberg 2011) which revealed no collinearity issue (all vif $<1.3$ in all the models).

\section{Results}

\section{Energy balance}

In our first model testing the effect of socioecological factors on chimpanzee energy balance (UCP levels), we found that the full model was not significantly different from the null model (LRT: $\chi^{2}=16.81, \mathrm{df}=11, P=0.052$ ). However, since the $P$ value was very close to the arbitrary threshold of 0.05 , we investigated the significance of the single predictors in the model, keeping in mind that the results should be interpreted with caution.

After removing the non-significant interaction between food availability and sex $\left(\chi^{2}=0.73, P=0.393\right)$ from Model 1 , we found that food availability had a significant positive effect on energy balance in both sexes with UCP levels being higher when food was more abundant (Model 1: $\chi^{2}=4.19$, $P=0.040$, Table 4, Fig. 1). Except for a few months in the year (e.g. October and November 2017 and February 2018), monthly chimpanzee UCP levels and monthly food availability covaried throughout the year (Fig. S1).

In Model 1, the interaction between individual dominance rank, sex and presence of oestrus females was significant $\left(\chi^{2}=5.62, P=0.018\right)$ indicating that the presence of oestrus female mediated the relationship between dominance rank and UCP levels and that this relationship differed between male and female chimpanzees (Table 4, Fig. 2). More specifically, higher ranking females had higher UCP levels than lowranking females in the absence of oestrus females (Fig. 2a) but slightly lower UCP levels than low-ranking females when oestrus females were present (Fig. 2b). Among males, highranking males had lower UCP levels than low-ranking males (Fig. 2c) in the absence of oestrus females and higher UCP levels than low-ranking males in the presence of oestrus females (Fig. 2d). Throughout the study, we observed only one rank reversal between the number 2 and 3 in males and all other ranks remained stable in both sexes.
In addition to our test predictors, in Model 1, we did not find a significant effect of average daily party size on UCP levels ( $\left.\chi^{2}=0.07, P=0.788\right)$; in contrast, time of sample collection had a significant positive effect on UCP levels $\left(\chi^{2}=\right.$ 5.27, $P=.022)$ with UCP levels being lower in the morning samples than in the afternoon samples (Supplementary material, Fig. S2).

\section{Energy intake and feeding time}

Our calculation of energy intake based on behavioural observations of focal chimpanzee feeding behaviour was not significantly affected by the social (dominance rank and the presence of oestrus females) and ecological (food availability) variables we investigated (full-null model comparison in Model 2a, LRT: $\chi^{2}=5.22, \mathrm{df}=9$, $P=0.815)$. In contrast, the socioecological factors significantly affected chimpanzee feeding time (full-null model comparison in Model 2b, LRT: $\chi^{2}=22.15$, df $=$ $9, P=0.008)$. None of the interaction terms was significant in Model $2 \mathrm{~b}$ (all $P>0.07$ ). After removing the non-significant interactions from the model, we found that chimpanzees from both sexes spent less time feeding when food availability was high $\left(\chi^{2}=8.13, P=\right.$ 0.004, Fig. 3, Table 4) and when they were in large parties $\left(\chi^{2}=5.51, P=0.023\right.$, Fig. S3, Table 4).

\section{Energy that chimpanzees spent on activities}

The socioecological factors under investigation in our study also significantly affected the energy that a chimpanzee spent on activities (full-null model comparison in Model 3, LRT: $\left.\chi^{2}=31.68, \mathrm{df}=9, P<0.001\right)$. None of the interaction terms was significant in Model 3 (all $P>0.24$ ). After removing these non-significant interactions from the model, we found that chimpanzees of both sexes spent more energy on activities when food was more abundant $\left(\chi^{2}=18.23, P<0.001\right.$, Fig. 4, Table 4) and highranking individuals of both sexes spent less energy on activities than lower ranking one $\left(\chi^{2}=4.72, P=0.030\right.$, Fig. 5, Table 4).

\section{Relationship between UCP levels and behavioural measures of energy intake and energy spent on activities}

We could not detect a significant effect of our behavioural measures of energy intake and energy spent on activities on UCP levels (full-null model comparison in Model 4, LRT: $\left.\chi^{2}=1.86, \mathrm{df}=2, P=0.394\right)$. 
Table 4 Results of the four generalized linear mixed models examining the effect of ecological (food availability) and social (dominance rank, presence of oestrus females) on urinary C-peptide level (Model 1), energy intake (Model 2a), feeding time (Model 2b) and energy spent on activities
(Model 3), and of a fifth model assessing the effect of energy intake and energy spent during activities on UCP levels (Model 4) in wild western chimpanzees

\begin{tabular}{|c|c|c|c|c|c|c|}
\hline Response variable & Estimate & $\mathrm{SE}$ & $\mathrm{CI}_{\text {low }}$ & $\mathrm{CI}_{\text {high }}$ & $\chi^{2}$ & $P$ \\
\hline \multicolumn{7}{|l|}{$\begin{array}{l}\text { Model 1. UCP levels (energy balance) } \\
\text { Full model vs. null model LRT: } \chi^{2}=16.81, \mathrm{df}=9, P=0.052\end{array}$} \\
\hline Intercept & 1.69 & 0.19 & 1.33 & 2.05 & & \\
\hline Sex (females) & -0.69 & 0.32 & -1.30 & -0.11 & & \\
\hline Dominance rank & 0.13 & 0.18 & -0.23 & 0.51 & & \\
\hline Presence of oestrus females & -0.48 & 0.18 & -.086 & -0.14 & & \\
\hline Mean party size & 0.01 & 0.10 & -0.19 & 0.20 & 0.07 & 0.788 \\
\hline Monthly food availability & 0.15 & 0.07 & 0.005 & 0.30 & 4.19 & 0.040 \\
\hline Urine collection time & 0.14 & 0.06 & 0.02 & 0.26 & 5.27 & 0.022 \\
\hline Sex (females): dominance rank: presence of oestrus females & 0.65 & 0.28 & 0.12 & 1.26 & 5.62 & 0.018 \\
\hline \multicolumn{7}{|l|}{$\begin{array}{l}\text { Model 2a. Energy intake } \\
\text { Full model vs. null model LRT: } \chi^{2}=5.22, \mathrm{df}=9, P=0.815\end{array}$} \\
\hline \multicolumn{7}{|l|}{$\begin{array}{l}\text { Model 2b. Feeding time } \\
\text { Full model vs. null model LRT: } \chi^{2}=22.15, \mathrm{df}=9, P=0.008\end{array}$} \\
\hline Intercept & 0.38 & 0.01 & 0.35 & 0.40 & & \\
\hline Sex (females) & -0.02 & 0.02 & -0.05 & 0.40 & 0.87 & 0.351 \\
\hline Dominance rank & -0.02 & 0.008 & -0.03 & 0.002 & 3.78 & 0.052 \\
\hline Presence of oestrus females & 0.01 & 0.02 & -0.03 & 0.04 & 0.29 & 0.591 \\
\hline Mean party size & -0.02 & 0.009 & -0.02 & -0.004 & 5.51 & 0.023 \\
\hline Monthly food availability & -0.03 & 0.009 & -0.04 & -0.01 & 8.13 & 0.004 \\
\hline \multicolumn{7}{|l|}{$\begin{array}{l}\text { Model 3. Energy spent on activities } \\
\text { Full model vs. null model LRT: } \chi^{2}=31.68, \mathrm{df}=9, P<0.001\end{array}$} \\
\hline Intercept & 929.69 & 27.76 & 1508.81 & 1671.10 & & \\
\hline Sex (females) & 38.19 & 34.30 & 9.92 & 191.74 & 1.28 & 0.258 \\
\hline Dominance rank & -36.02 & 16.77 & -94.22 & 6.50 & 4.72 & 0.030 \\
\hline Presence of oestrus females & 55.50 & 36.94 & -36.97 & 174.75 & 2.32 & 0.127 \\
\hline Mean party size & 0.12 & 17.17 & -34.42 & 64.92 & 0.00 & 0.995 \\
\hline Monthly food availability & 90.67 & 18.35 & 63.78 & 173.84 & 18.23 & $<0.001$ \\
\hline $\begin{array}{l}\text { Model 4. Energy intake, energy spent on activities and UCP } \\
\text { Full model vs. null model LRT: } \chi^{2}=1.86, \mathrm{df}=2, P=0.394\end{array}$ & & & & & & \\
\hline
\end{tabular}

SE indicates the standard error of the estimate for each predictor. The coded level for each categorical predictor is indicated in bracket. Control predictors are italicized. Significant $P$ value $(P<0.05)$ are indicated in bold. $\mathrm{CI}_{\mathrm{low}}$ and $\mathrm{CI}_{\text {high }}$ indicate the lower and upper limits of the $95 \%$ confidence interval for the estimates of each predictor

\section{Discussion}

Our study provides new insights into the association between socioecological factors and energetic conditions in western chimpanzees. We found an effect of food availability on energy balance in both females and males. As predicted, social factors such as dominance rank and the presence of oestrus females impacted males and females differently. As expected from socioecological theories (Sterck et al. 1997; Koenig 2002), dominance rank was positively correlated with energy balance in females. Yet this positive effect was only found in the absence of oestrus females in the party. The effect disappeared in the presence of oestrus females. In contrast, in males, we found a negative effect of dominance rank on energy balance when there was no oestrus female present but a positive effect in the presence of oestrus females.

It is important to note that despite the significance of our test predictor in Model 1 assessing the socioecological factors influencing UCP levels in chimpanzees, the full versus null model comparison was not significant so the pattern described here should be considered with caution. In the rest of the analysis, we could not isolate a clear contribution of our behavioural measure of energy intake and energy spent on activities to explain the combined effect of sex and dominance rank on energy balance measured using UCP levels. In fact, we could not detect a combined effect of rank and sex on our 
Fig. 1 Effect of food availability on UCP levels in wild western chimpanzees. Each dot represents the average UCP levels (in ng/mg creatinine) for each individual each month. The area of the dot is proportional to the number of samples collected on that individual that month. The blue line depicts the model prediction for the effect of food availability on UCP levels (Model 1)

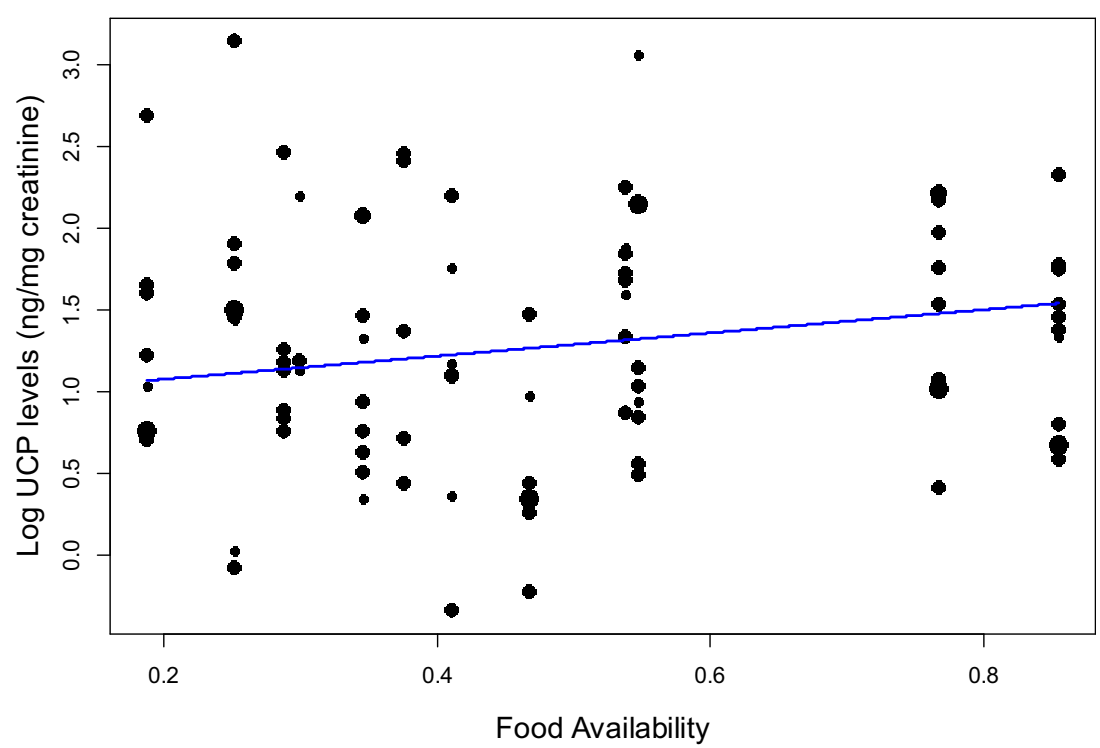

behavioural measures of chimpanzee energy intake and energy spent on activities with individuals from both sexes feeding for shorter durations and spending more energy on activities when food availability was high and feeding longer in smaller

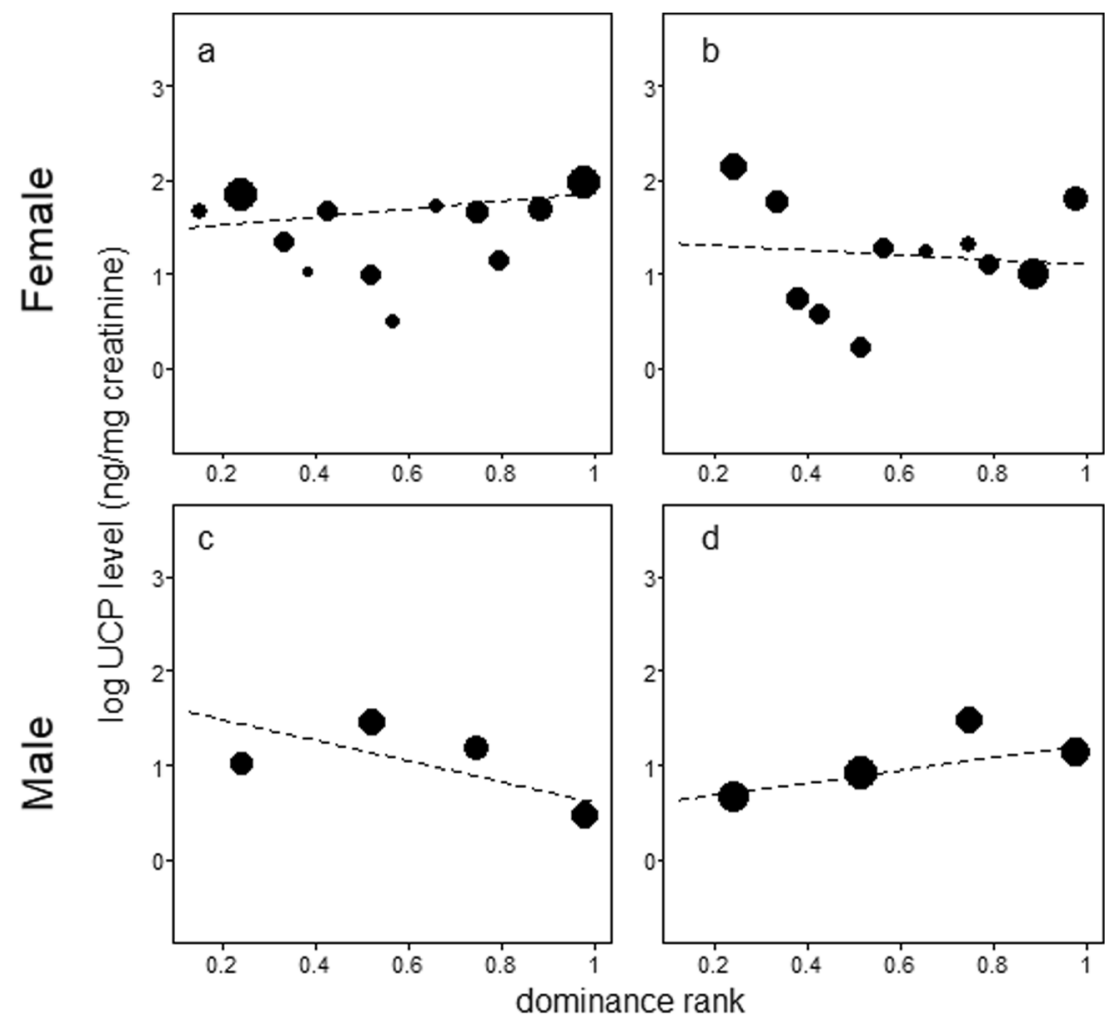

No oestrus female

Fig. 2 Relation between UCP levels and social (dominance rank*, presence of oestrus females) factors in males and females western chimpanzees. (a) UCP levels of females in the absence of oestrus females within the party; (b) UCP levels of females in the presence of oestrus females within the party; (c) UCP levels of males in the absence of oestrus females within the party; (d) UCP levels of males in the presence of oestrus females within the party. The dots in the graph represent the Elo-rating scores of each individual standardized within each sex. The black lines in each of the four panels indicate the model lines following the slope and intercept of the relationship between dominance rank and UCP levels predicted by Model 1 in the four conditions. Also note that while the interaction rank* sex* presence of oestrus female was significant in Model 1, the full-null model comparison in Model 1 was only close to significance $(P=0.052)$ so the relationships depicted here should be interpreted with caution 
Fig. 3 Effect of food availability on time spent feeding in wild western chimpanzees. Each dot represents the average time spent feeding (in percentage of observation time) for each individual each month. The area of the dot is proportional to the number of observation days for that individual that month. The blue line depicts the model prediction for the effect of food availability on feeding time (Model 2b)

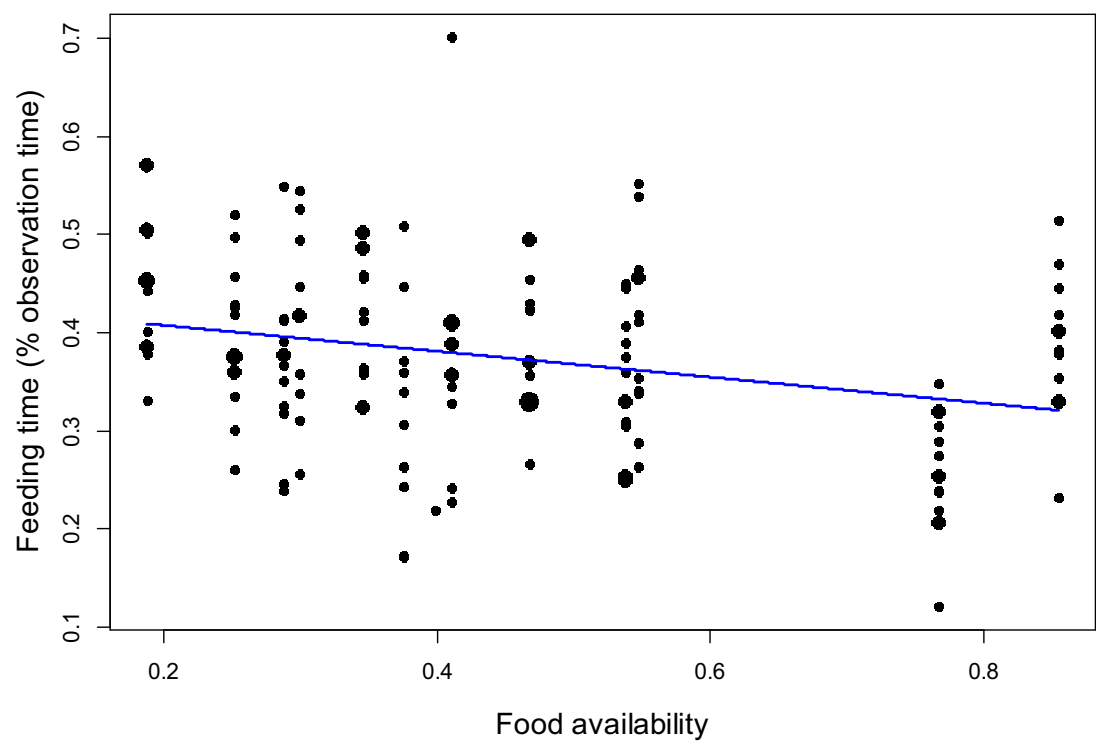

parties. We also found that high-ranking male and female chimpanzees spent less energy on activities. When testing directly the relationship between our hormonal and behavioural energetic measures (Model 4), we could not detect a significant link between UCP levels and energy intake or energy spent on activities.

Interestingly, and contrary to the prediction derived from socioecological theories (Emlen and Oring 1977; CluttonBrock and Harvey 1978; Clutton-Brock et al. 1989; Sterck et al. 1997; Kappeler 2000; Koenig 2002; Tobias et al. 2012), in our study, the positive effect of food availability on feeding time and energy balance was of a similar magnitude for male and female chimpanzees since the interaction between sex and food availability was not significant in Model 1 and Model 2b. N'Guessan et al. (2009) found the same relationship between energy balance and food availability in both sexes in the same chimpanzee population, but based on behavioural assessment of energy balance, although similar results were found in male eastern (Emery Thompson et al. 2009, 2014) and western chimpanzees (Wessling et al. 2018a), assessing the difference between sexes was not possible, since Emery Thompson et al. (2009) used males only and Emery Thompson et al. (2014) and Wessling et al. (2018a) did not consider the interaction between food availability and sex. In contrast, our study suggests a similar magnitude of this effect in both sexes. Yet, this result calls for caution since the full and null model comparison in Model 1 is slightly above the significance threshold with $P=0.052$, and our data set consists of a small sample size. Our results, however, show that, under certain conditions, ecological
Fig. 4 Effect of food availability on energy spent on activities in wild western chimpanzees. Each dot represents the average daily energy spent on activities (in $\mathrm{kcal} /$ day) for each individual each month. The area of the dot is proportional to the number of observation days for that individual that month. The blue line depicts the model prediction for the effect of food availability on energy spent on activities (Model 3)

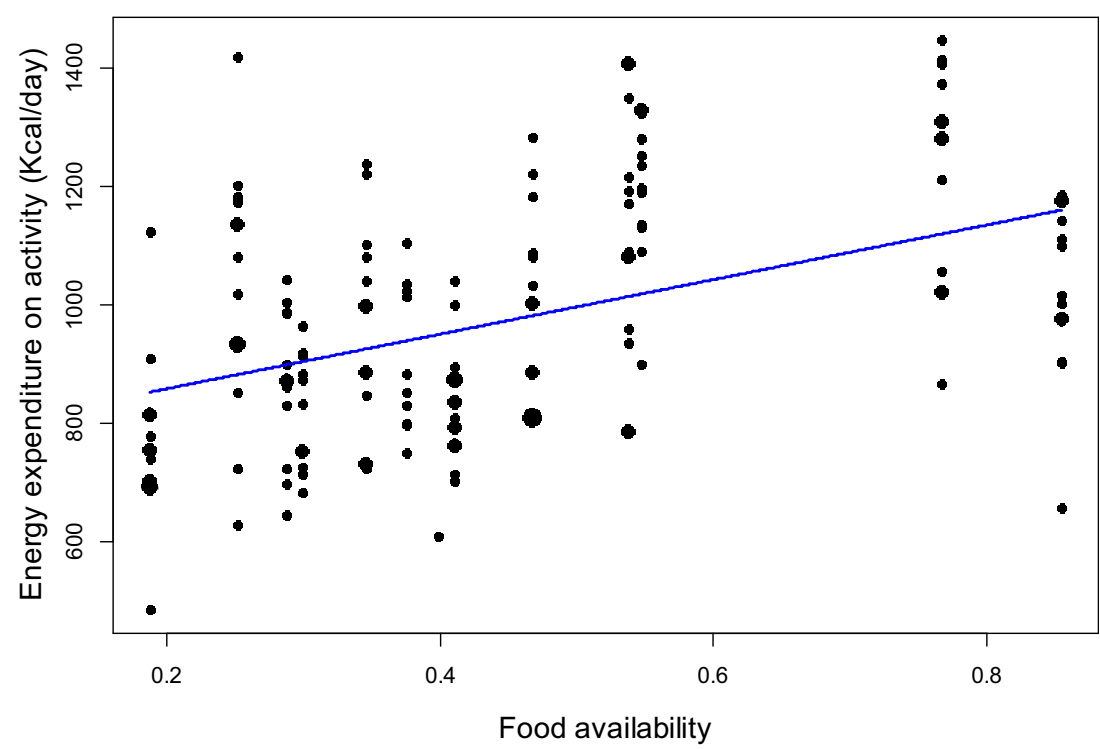


Fig. 5 Effect of dominance rank on energy spent on activities in wild western chimpanzees. Each dot represents the average daily energy spent on activities (in $\mathrm{kcal} /$ day) for each individual. The area of the dot is proportional to the number of observation days for that individual. The blue line depicts the model prediction for the effect of dominance rank on energy spent on activities (Model 3)

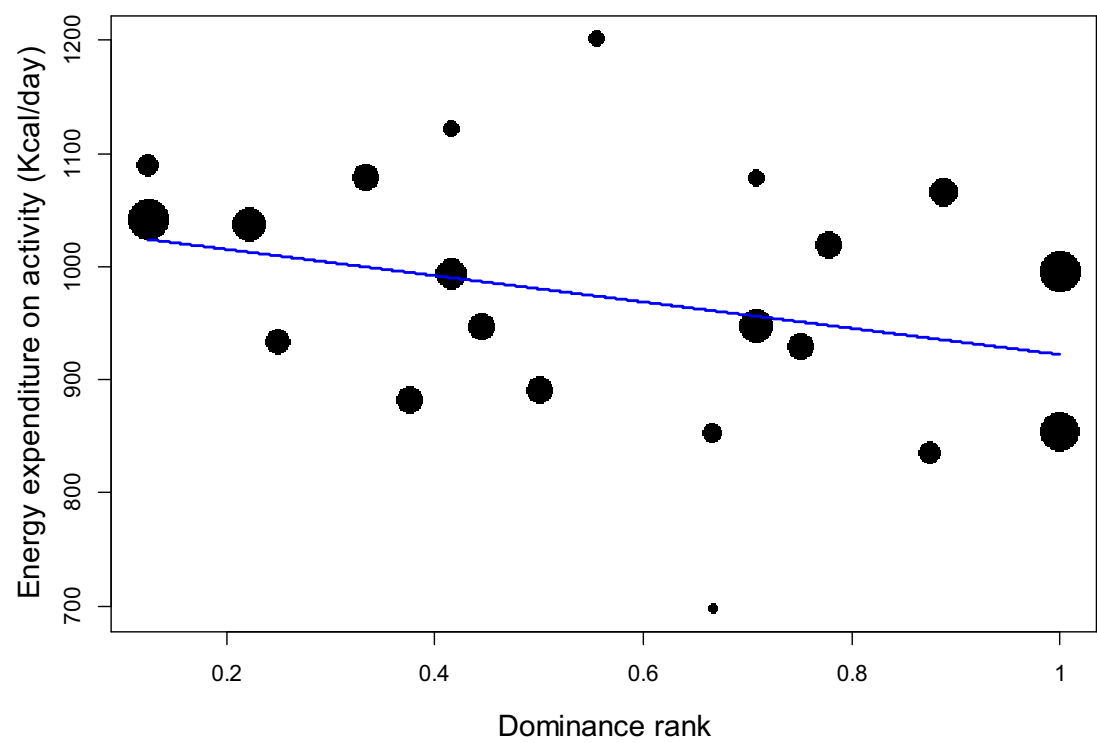

factors can impact male and female energetics equally, and should encourage future studies to replicate this analysis in larger chimpanzee communities and with larger datasets.

The relationship between UCP levels and food availability was significant but not fully linear and, in certain months, UCP levels were high when the food availability was low and vice-versa (Fig. S1). Those months were characterized either by a low food availability associated with an abundance of highly calorific fruit (i.e. Coula edulis) or by frequent hunting which is relatively independent of food availability (Stanford et al. 1994; Boesch and Boesch-Achermann 2000; Gilby and Wrangham 2007) but may lead to high energy gains. Indeed, it was suggested that the nutritional importance of meat and bone marrow consumption in the chimpanzee diet could be one of the main factors which drove the evolution of chimpanzees hunting behaviour (Boesch 1994; Stanford et al. 1994; Mitani and Watts 2001). This indicates that it was not only the availability of food in large quantities (our measure) which increased individual energy balance but also the food quality (i.e. its nutritional value). Therefore, we encourage future studies to develop phenological indexes which incorporate not only food quantity but also a nutritional value index.

Our results on the behavioural measures of energy intake and energy spent on activities highlight the difficulty in using these measures as a proxy for individual energy balance. In fact, we found that chimpanzees spent less time feeding and spent more energy on activities when food availability was high but still had a more positive energy balance during these periods (higher UCP levels). Our results indicate that chimpanzees may have evolved a behavioural adaptation documented in other studies consisting of feeding longer (N'Guessan et al. 2009) and on lower quality food (Doran 1997) during periods of food scarcity while refraining from engaging in energetically costly activities. These results also emphasize the value of non-invasive physiological measures of wild mammal energetic status in addition to behavioural measures.

Besides the ecological effect, we also found an influence of dominance rank on individual energetic conditions which differs between males and females and was conditional on the presence or absence of oestrus females. In the absence of oestrus females in the parties, the energy balance of highranking females was higher than that of low-ranking females. This finding is in line with general socioecological theories predicting strong female-female competition for access to food resources (Emlen and Oring 1977; Clutton-Brock and Harvey 1978; Clutton-Brock et al. 1989; Tobias et al. 2012), and, as a result, an effect of dominance on food acquisition as observed in many primate species (Barton and Whiten 1993; Saito 1996) including western female chimpanzees (Wittig and Boesch 2003) and in spotted hyenas (Watts et al. 2009). This proximate effect of dominance rank on female access to food is likely to be the main mechanism leading to enhanced fitness in high-ranking females documented in several mammalian species (Pusey et al. 1997; King and Allainé 2002; von Holst et al. 2002; Majolo et al. 2012), including primates (Majolo et al. 2012). Our study contributes to our understanding of the mechanisms linking high dominance status and fitness benefits in chimpanzees. In particular, we show that the priority of access to high-quality food by high-ranking females (Pusey et al. 1997; Murray et al. 2006) leads to more positive energy balance in these females (our study) which is one potential main mechanism explaining why high-ranking females produce offspring which are more likely to survive (Goodall 1977, 1986). Surprisingly, in our study, this energetic advantage of being a high-ranking female disappeared when oestrus females were present $(60 \%$ of the observation 
days) suggesting that the social dynamics associated with male-male mating competition impacts female energetics as well. The presence of males around oestrus females may increase feeding competition and reduce female feeding opportunities, as observed in eastern chimpanzees where females had lower UCP levels when associating with more males than when associating with more females (Emery Thompson et al. 2014). In several animal species in which males can obtain coercive mating, conflicts of interest between the sexes are likely to arise (Trivers 1972; Parker 1979; Clutton-Brock and Parker 1995), and receptive females are more often the victims of aggressions. Male chimpanzees often use coercion to access fertile females in order to increase their mating success, which in turn incurs a high energetic cost for the female victim (Muller et al. 2007). In chimpanzees, high-ranking females are often the oldest (Wittig and Boesch 2003), and therefore, the most experienced mothers whose offspring are more likely to survival to adulthood (Boesch 1997; Pusey et al. 1997). This may be why males prefer high-ranking females as mating partners (Muller et al. 2006). In turn, highranking females receive more aggression when fertile compared to low-ranking females and thus bear a stronger energetic cost which may limit the benefits of dominance rank on their energetic condition. However, the aggression rate of males towards oestrus females is unlikely to be the main driver of the observed pattern in our study community because coercion is rare in Taï (Stumpf and Boesch 2005). Even though it is relatively rare, male aggression towards oestrus females is used by less preferred males in Taï, but does not seem to constrain female mating choice (Stumpf and Boesch 2005). In our study, the rank effect did not only disappear for fertile females since the effect of dominance rank on female energy balance was alleviated across all females. This indicates that the presence of maximally tumescent females modifies the social, foraging and ranging dynamic of the community in a way that removes the energetic advantages of high-ranking females. In fact, in Taï, the presence of oestrus females increases the number of males but also the number of females in the party (Anderson et al. 2002) which potentially generates different competitive dynamics. This is mostly stemming from the high attractiveness of receptive females for both males and females leading to males following the ranging patterns of receptive females (Emlen and Oring 1977; Mitani et al. 1996; Kappeler 2000). In turn, this may lead to a shift in "power" by placing the foraging decisions and the priority of access to richer food patches in the hands of the fertile females rather than systematically in the hands of highranking females. However, the reduced rank effect on energy balance across all females during periods of mating competition may be due to the influence of a few popular females, given our sample size. Future studies should investigate this in more detail, focusing on the effect of male-male mating competition on female access to food and grouping patterns using behavioural measures.

In contrast to the female pattern, we observed a negative relationship between dominance and energy balance in males in the absence of maximally tumescent females, with highranking males having lower UCP levels than low-ranking males. This pattern could reflect (1) a lower energy intake for high-ranking males which was not captured by our behavioural measures and/or (2) higher energy expenditure for highranking males which is unlikely given our finding that highranking males spend less energy on activities than lowranking males (Model 3) and/or (3) a higher metabolic rate in higher ranking than in lower ranking males stemming from higher physiological or psychological stress (Hollstein et al. 2020) as evidenced by higher levels of cortisol reported in high-ranking male eastern chimpanzees (Muller and Wrangham 2004; Gesquiere et al. 2011). Regardless of the precise effects causing more negative energy balance in high-ranking male chimpanzees, our results, in accordance with other studies on eastern chimpanzees (Emery Thompson et al. 2009; Georgiev 2012), emphasize the tradeoff between investment into social status (Goodall 1986) and energetic allocation for other functions such as body maintenance (Komdeur 2001; Low 2006; Schubert et al. 2009). Interestingly, the presence of oestrus females reversed the effect of dominance status on males' energy balance. This specific result differs from what was documented in eastern chimpanzees where high-ranking males had lower energy balance (UCP levels) than low-ranking males also in periods with high male-male mating competition (Emery Thompson et al. 2009; Georgiev 2012). Eastern male chimpanzees, regardless of their rank, appear to suffer an energetic cost when tumescent females were present in the party since they reduced their feeding time (Georgiev et al. 2014). Feeding time reduction might be associated with an increased focus on the sexually receptive female as was documented during mate guarding in macaques and baboons (Bercovitch 1983; Alberts et al. 1996; Girard-Buttoz et al. 2014a, b). In our chimpanzee population in Taï, males coerce females less than in the eastern populations (Boesch et al. 2008) and females have more opportunity to express a choice in their mating partners. Across mammals, including primates, females often prefer to mate with highranking males (Cox and Le Boeuf 1977; Andersson 1994; van Schaik 1996; Berglund et al. 1996; Sterck et al. 1997; Knott et al. 2010) which makes it even harder for lowranking males to access female mating partners in Taï than in eastern chimpanzees where the female choice is reduced. Therefore, low-ranking male chimpanzees in Taï might have to monitor female behaviour (thereby reducing their feeding time), avoid retaliation from high-ranking males via engaging in sneaky copulations (Nurnberg et al. 1994; Setchell 2008) and gain the favour of females to be chosen for these copulations, such as through food sharing (Gomes and Boesch 
2009). In turn, this could lead to a higher energetic cost of the presence of oestrus females for low-ranking than for highranking males. Future studies should investigate whether low-ranking males are truly constrained in their feeding time during periods of intense male-male competition.

Genetic relatedness is potentially an additional factor contributing to the observed pattern. In fact, our study community was composed by only four males and eight females and the mating competition was possibly stronger between low-ranking males because each of them was genetically related to one or two females in the community. The alpha males copulated with $100 \%$ of females while the beta copulated with $87 \%$ and the two lowranking males in turn copulated with $75 \%$ of the females showing that the mating competition is not the same for all males. The low-ranking males had kin in the community and did not compete for access to fertile females when those females were kin which may have created periods of lowered mating competition for the high-ranking males. In turn, this may have alleviated some of the energetic costs of mating competition for higher ranking males and explained the observed pattern in our study.

It is important to note that despite its effect on energy balance, we could not find a significant effect of dominance rank on chimpanzee energy intake. We found a significant negative effect of dominance rank on the energy spent on activities by chimpanzees but this effect (unlike the effect on UCP levels) did not differ between males and females and was not depending on the presence of oestrus females. Therefore, it is likely that the lack of fit between the statistical models using behavioural measures of energy intake and energy spent on activities and the results on UCP levels are due to the level of error in estimating energy intake and energy spent on activities using behavioural observations. In fact, several errors can be introduced at several steps in estimating energy intake from digestibility of wild food (Conklin-Brittain et al. 2006), variation in fruit size, portion of the food item eaten, differential nutritional value of the food items in different parts of the canopy (e.g. for fruits (Houle et al. 2007, 2014; Gullo et al. 2014)). With such bias, it is possible that despite the best efforts to collect detailed feeding data, a crude measure of feeding time may more clearly reveal some socioecological phenomenon (linked to the party size), as we observed. Thus, our results on energy spent on activities but even more one energy intake should be taken with caution. It is likely that under other conditions, sex, rank, food availability and presence of oestrus females do not affect energy intake. UCP measures, although prone to some measurement error, appear a more suited integrative measure to reveal the socioecological processes underlying primate energetics, at least in our study.

\section{Conclusion}

Altogether, our results indicate that feeding and mating competition affect male and female chimpanzee energetic status.
In turn, this suggests that social strategies and behavioural adaptation can prove useful adaptations to sustain high energetic demands due to ecological and social constraints. Our findings emphasize the importance of ecological factors such as food availability for male energetics and we encourage future study to integrate both sexes in socioecological analyses. On the other hand, we also characterized the importance of the degree of mating competition for the energetics not only of males but also of females since the presence of oestrus females alleviated the energetic advantages of being high ranking in female chimpanzees. Our results also emphasize the complexity of the effect of dominance rank on males energy balance and highlight how the community size and degree of genetic relatedness between individuals can be important in shaping this relationship and producing contrasting patterns to those observed in larger communities. To conclude, we would like to encourage future studies on feeding competition and socioecological energetics to incorporate both sexes and compare male and female patterns. This enterprise will provide a more comprehensive and balanced insight into the complex mechanisms impacting wild animal energetic status. Such studies can provide some contrasts and nuances to some tests of general socioecological theories which often focus on the energetic costs of mating competition for males and of feeding competition for females and do not assess these effects in both sexes simultaneously.

Supplementary Information The online version contains supplementary material available at https://doi.org/10.1007/s00265-020-02935-9.

Acknowledgments We thank the Ivorian Ministry of Higher Education and Scientific Research and the Office Ivoirien des Parcs et Reserves of Côte d'Ivoire for permission to conduct the study. We are grateful to the staff of the Taï Chimpanzee Project for assistance in the field. Thanks to Jared Cobin, Janette Gleiche and Verena Behringer of the Lab for Field Endocrinology at MPI EVA, Richard McElreath for his continuous support and members of the Department of Primatology at MPI EVA for helpful comments on various versions of this manuscript. The Max Planck Society provides core funding for the Taï Chimpanzee Project since 1997. We thank David P. Watts and three anonymous reviewers for their constructive comments on a previous version of this manuscript.

Funding Open Access funding enabled and organized by Projekt DEAL. $\mathrm{PDV}$ received a $\mathrm{PhD}$ grant from the Centre Suisse de Recherches Scientifiques in Côte d'Ivoire and the Max Planck Institute for Evolutionary Anthropology. The Max Planck Society provides core funding for the Taï Chimpanzee Project since 1997.

Data availability The datasets generated during and/or analyzed during the current study are available from the corresponding author on reasonable request.

\section{Compliance with ethical standards}

Conflict of interest The authors declare that they have no conflict of interest. 
Ethical approval This study was approved by the Ministère de l'Enseignement Supérieur et de la Recherche Scientifique and the Ministère de Eaux et Forêts in Côte d'Ivoire, and the Office Ivoirien des Parcs et Réserves. Ivorian Ministry of Higher Education and Scientific Research and the Office Ivoirien des Parcs et Reserves of Côte d'Ivoire. The non-invasive methods of this study were approved by the Ethic Commission of the Max Planck Society. All applicable international, national and/or institutional guidelines for the use of animals were followed.

Ethical statement This manuscript is all original work, has not been published previously (partially or in full). No data in this manuscript has been fabricated or manipulated, and all authors have given consent to submit this manuscript and have contributed sufficiently to the scientific work.

Open Access This article is licensed under a Creative Commons Attribution 4.0 International License, which permits use, sharing, adaptation, distribution and reproduction in any medium or format, as long as you give appropriate credit to the original author(s) and the source, provide a link to the Creative Commons licence, and indicate if changes were made. The images or other third party material in this article are included in the article's Creative Commons licence, unless indicated otherwise in a credit line to the material. If material is not included in the article's Creative Commons licence and your intended use is not permitted by statutory regulation or exceeds the permitted use, you will need to obtain permission directly from the copyright holder. To view a copy of this licence, visit http://creativecommons.org/licenses/by/4.0/.

\section{References}

Alberts SC, Altmann J, Wilson ML (1996) Mate guarding constrains foraging activity of male baboons. Anim Behav 51:1269-1277

Altmann J (1974) Observational study of behavior: sampling methods. Behaviour 49:227-266

Altmann J, Samuels A (1992) Costs of maternal care: infant-carrying in baboons. Behav Ecol Sociobiol 29:391-398. https://doi.org/10. 1007/BF00170168

Anderson DP, Nordheim EV, Boesch C, Moermond TC (2002) Factors influencing fission-fusion grouping in chimpanzees in the Tai National Park, Côte d'Ivoire. In: Boesch C, Hohmann G, Marchant LF (eds) Behavioural diversity in chimpanzees and bonobos. Cambridge University Press, Cambridge, pp 90-101

Andersson MB (1994) Sexual selection. Princeton University Press, Princeton

Baayen RH (2008) Analyzing linguistic data: a practical introduction to statistics using R. Cambridge University Press, Cambridge

Baayen RH, Davidson DJ, Bates DM (2008) Mixed-effects modeling with crossed random effects for subjects and items. J Mem Lang 59:390-412

Barr DJ, Levy R, Scheepers C, Tily HJ (2013) Random effects structure for confirmatory hypothesis testing: keep it maximal. J Mem Lang $68: 255-278$

Barton RA, Whiten A (1993) Feeding competition among female olive baboons, Papio anubis. Anim Behav 46:777-789

Bates D, Mächler M, Bolker B, Walker S (2015) Fitting linear mixedeffects models using lme4. J Stat Softw 67:1-48

Bercovitch FB (1983) Time budgets and consortships in olive baboons (Papio anubis). Folia Primatol 41:180-190

Berglund A, Bisazza A, Pilastro A (1996) Armaments and ornaments: an evolutionary explanation of traits of dual utility. Biol J Linn Soc 58: 385-399. https://doi.org/10.1111/j.1095-8312.1996.tb01442.x
Boesch C (1994) Cooperative hunting in wild chimpanzees. Anim Behav 48:653-667

Boesch C (1997) Evidence for dominant wild female chimpanzees investing more in sons. Anim Behav 54:811-815

Boesch C, Boesch-Achermann H (2000) The chimpanzees of the Taii Forest: behavioural ecology and evolution. Oxford University Press, Oxford

Boesch C, Crockford C, Herbinger I, Wittig R, Moebius Y, Normand E (2008) Intergroup conflicts among chimpanzees in Tai National Park: lethal violence and the female perspective. Am J Primatol 70:519-532

Bosaeus I, Daneryd P, Lundholm K (2002) Dietary intake, resting energy expenditure, weight loss and survival in cancer patients. J Nutr 132: 3465S-3466S. https://doi.org/10.1093/jn/132.11.3465S

Buzzard PJ (2006) Ecological partitioning of Cercopithecus campbelli, C. petaurista, and C. diana in the Taï Forest. Int J Primatol 27:529558

Bygott J (1979) Agonistic behaviour, dominance, and social structure in wild chimpanzees of the Gombe National Park. In: Hamburg DA, McCown ER (eds) The great apes. The Benjamin/Cummings, Menlo Park, pp 405-428

Charnov EL, Berrigan D (1993) Why do female primates have such long lifespans and so few babies? Or life in the slow lane. Evol Anthropol 1:191-194. https://doi.org/10.1002/evan.1360010604

Clutton-Brock TH, Harvey PH (1978) Mammals, resources and reproductive strategies. Nature 273:191-195

Clutton-Brock TH, Parker GA (1995) Sexual coercion in animal societies. Anim Behav 49:1345-1365

Clutton-Brock TH, Albon SD, Guinness FE (1989) Fitness costs of gestation and lactation in wild mammals. Nature 337:260-262

Conklin-Brittain NL, Knott CD, Ham RWW (2006) Energy intake by wild chimpanzees and orangutans: methodological considerations and a preliminary comparison. In: Hohmann G, Robbins MM, Boesch C (eds) Feeding ecology in apes and other primates. Cambridge University Press, Cambridge, pp 445-571

Cox CR, Le Boeuf BJ (1977) Female incitation of male competition: a mechanism in sexual selection. Am Nat 111:317-335. https://doi. org $/ 10.1086 / 283163$

Deschner T, Kratzsch J, Hohmann G (2008) Urinary C-peptide as a method for monitoring body mass changes in captive bonobos (Pan paniscus). Horm Behav 54:620-626

Dobson AJ (2002) An introduction to generalized linear models, 2nd edn. Chapman and Hall/CRC Press, Boca Raton

Doran D (1997) Influence of seasonality on activity patterns, feeding behavior, ranging, and grouping patterns in Tai chimpanzees. Int J Primatol 18:183-206

Ellis L (1995) Dominance and reproductive success among nonhuman animals: a cross-species comparison. Ethol Sociobiol 16:257-333

Emery Thompson M (2017) Energetics of feeding, social behavior, and life history in non-human primates. Horm Behav 91:84-96. https:// doi.org/10.1016/j.yhbeh.2016.08.009

Emery Thompson M, Knott CD (2008) Urinary C-peptide of insulin as a non-invasive marker of energy balance in wild orangutans. Horm Behav 53:526-535

Emery Thompson M, Muller MN, Wrangham RW, Lwanga JS, Potts KB (2009) Urinary C-peptide tracks seasonal and individual variation in energy balance in wild chimpanzees. Horm Behav 55:299-305. https://doi.org/10.1016/j.yhbeh.2008.11.005

Emery Thompson M, Muller MN, Wrangham RW (2012) The energetics of lactation and the return to fecundity in wild chimpanzees. Behav Ecol 23:1234-1241. https://doi.org/10.1093/beheco/ars107

Emery Thompson M, Muller MN, Wrangham RW (2014) Male chimpanzees compromise the foraging success of their mates in Kibale National Park, Uganda. Behav Ecol Sociobiol 68:1973-1983. https://doi.org/10.1007/s00265-014-1803-y 
Emlen ST, Oring LW (1977) Ecology, sexual selection, and the evolution of mating systems. Science 197:215-223

Foerster S, Franz M, Murray CM, Gilby IC, Feldblum JT, Walker KK, Pusey AE (2016) Chimpanzee females queue but males compete for social status. Sci Rep 6:35404. https://doi.org/10.1038/srep35404

Fox J, Weisberg S (2011) Multivariate linear models in R. An appendix to an R companion to applied regression. Thousand Oaks, Los Angeles

Georgiev AV (2012) Energetic costs of reproductive effort in male chimpanzees. $\mathrm{PhD}$ thesis, Harvard University, Cambridge, MA

Georgiev AV, Russell AF, Emery Thompson M, Otali E, Muller MN, Wrangham RM (2014) The foraging costs of mating effort in male chimpanzees (Pan troglodytes schweinfurthii). Int J Primatol 35: 725-745. https://doi.org/10.1007/s10764-014-9788-y

Gesquiere LR, Learn NH, Simao MCM, Onyango PO, Alberts SJ, Altmann J (2011) Life at the top: rank and stress in wild male baboons. Science 333:357-360

Gilby IC, Wrangham RW (2007) Risk-prone hunting by chimpanzees (Pan troglodytes schweinfurthii) increases during periods of high diet quality. Behav Ecol Sociobiol 61:1771-1779. https://doi.org/ 10.1007/s00265-007-0410-6

Girard-Buttoz C, Higham JP, Heistermann M, Wedegärtner S, Maestripieri D, Engelhardt A (2011) Urinary C-peptide measurement as a marker of nutritional status in macaques. PLoS One 6: e18042. https://doi.org/10.1371/journal.pone.0018042

Girard-Buttoz C, Heistermann M, Rahmi E, Marzec A, Agil M, Fauzan PA, Engelhardt A (2014a) Mate-guarding constrains feeding activity but not energetic status of wild male long-tailed macaques (Macaca fascicularis). Behav Ecol Sociobiol 68:583-595. https:// doi.org/10.1007/s00265-013-1673-8

Girard-Buttoz C, Heistermann M, Rahmi E, Agil M, Fauzan PA, Engelhardt A (2014b) Costs of mate-guarding in wild male longtailed macaques (Macaca fascicularis): physiological stress and aggression. Horm Behav 66:637-648. https://doi.org/10.1016/j.yhbeh. 2014.09.003

Gomes CM, Boesch C (2009) Wild chimpanzees exchange meat for sex on a long-term basis. PLoS One 4:e5116. https://doi.org/10.1371/ journal.pone.0005116

Gomes CM, Mundry R, Boesch C (2009) Long-term reciprocation of grooming in wild West African chimpanzees. Proc R Soc Lond B 276:699-706. https://doi.org/10.1098/rspb.2008.1324

Goodall J (1977) Infant killing and cannibalism in free-living chimpanzees. Folia Primatol 28:259-282

Goodall J (1986) The chimpanzees of Gombe: patterns of behavior. Harvard University Press, Cambridge

Greengrass E (2005) Sociability and dominance among female chimpanzees at Gombe. $\mathrm{PhD}$ thesis, University of Bristol, Bristol, UK

Gullo G, Motisi A, Zappia R, Dattola D, Diamanti J, Mezzetti B (2014) Rootstock and fruit canopy position affect peach [Prunus persica (L.) Batsch] (cv. Rich May) plant productivity and fruit sensorial and nutritional quality. Food Chem 153:234-242. https://doi.org/10. 1016/j.foodchem.2013.12.056

Günther MM, Boesch C (1993) Energetic cost of nut-cracking behaviour in wild chimpanzees. In: Preuschoft H, Chivers DJ (eds) Hands of primates. Springer, Vienna, pp 109-129

Hanna JB, Schmitt D, Griffin TM (2008) The energetic cost of climbing in primates. Science 320:898. https://doi.org/10.1126/science. 1155504

Higham JP, Heistermann M, Maestripieri D (2011) The energetics of male-male endurance rivalry in free-ranging rhesus macaques, Macaca mulatta. Anim Behav 81:1001-1007

Hobbs NT (1989) Linking energy balance to survival in mule deer: development and test of a simulation model. Wildlife Monogr 101:139

Hollstein T, Basolo A, Ando T, Votruba SB, Krakoff J, Piaggi P (2020) Urinary norepinephrine is a metabolic determinant of 24-hour energy expenditure and sleeping metabolic rate in adult humans. J Clin Endocrinol Metab 105:1145-1156

Houle A, Chapman CA, Vickery WL (2007) Intra tree variation in fruit production and implications for primate foraging. Int J Primatol 28: $1197-1217$

Houle A, Conklin-Brittain NL, Wrangham RW (2014) Vertical stratification of the nutritional value of fruit: macronutrients and condensed tannins. Am J Primatol 76:1207-1232

Isabirye-Basuta $\mathrm{G}$ (1988) Food competition among individuals in a freeranging chimpanzee community in kibale forest, Uganda. Behaviour 105:135-147. https://doi.org/10.1163/156853988X00485

Isbell LA, Pruetz JD, Lewis M, Young TP (1999) Rank differences in ecological behavior: a comparative study of patas monkeys (Erythrocebus patas) and vervets (Cercopithecus aethiops). Int $\mathrm{J}$ Primatol 20:257-272

Isler K, van Schaik CP (2009) The expensive brain: a framework for explaining evolutionary changes in brain size. J Hum Evol 57: 392-400. https://doi.org/10.1016/j.jhevol.2009.04.009

Janmaat KRL, Ban SD, Boesch C (2013) Chimpanzees use long-term spatial memory to monitor large fruit trees and remember feeding experiences across seasons. Anim Behav 86:1183-1205. https://doi. org/10.1016/j.anbehav.2013.09.021

Kahlenberg SM, Emery Thompson M, Wrangham RW (2008) Female competition over core areas in Pan troglodytes schweinfurthii, Kibale National Park, Uganda. Int J Primatol 29:931-947. https:// doi.org/10.1007/s10764-008-9276-3

Kappeler PM (2000) Primate males: causes and consequences of variation in group composition. Cambridge University Press, Cambridge

King WJ, Allainé D (2002) Social, maternal, and environmental influences on reproductive success in female Alpine marmots (Marmota marmota). Can J Zool 80:2137-2143

Knott CD, Emery Thompson M, Stumpf RM, McIntyre MH (2010) Female reproductive strategies in orangutans, evidence for female choice and counterstrategies to infanticide in a species with frequent sexual coercion. Proc R Soc Lond B 277:105-113

Koenig A (2002) Competition for resources and its behavioral consequences among female primates. Int J Primatol 23:759-783

Komdeur J (2001) Mate guarding in the Seychelles warbler is energetically costly and adjusted to paternity risk. Proc R Soc Lond B 268: 2103-2111

Leonard WR, Robertson ML (1997) Comparative primate energetics and hominid evolution. Am J Phys Anthropol 102:265-281

Low M (2006) The energetic cost of mate guarding is correlated with territorial intrusions in the New Zealand stitchbird. Behav Ecol 17: 270-276

Majolo B, Lehmann J, de Bortoli VA, Schino G (2012) Fitness-related benefits of dominance in primates. Am J Phys Anthropol 147:652660

McCullagh P, Nelder JA (1989) Generalized linear models, 2nd edn. Chapman and Hall/CRC Press, Boca Raton

Melani F, Rubenstein AH, Oyer PE, Steiner DF (1970) Identification of proinsulin and C-peptide in human serum by a specific immunoassay. Proc Natl Acad Sci U S A 67:148-155

Mielke A, Samuni L, Preis A, Gogarten JF, Crockford C, Wittig RM (2017) Bystanders intervene to impede grooming in Western chimpanzees and sooty mangabeys. R Soc Open Sci 4:171296. https:// doi.org/10.1098/rsos.171296

Mitani JC, Watts DP (2001) Why do chimpanzees hunt and share meat? Anim Behav 61:915-924. https://doi.org/10.1006/anbe.2000.1681

Mitani JC, Gros-louis J, Manson JH (1996) Number of males in primate groups: comparative tests of competing hypotheses. Am J Primatol 38:315-332

Mitani JC, Call J, Kappeler PM, Palombit RA, Silk JB (eds) (2012) The evolution of primate societies. University of Chicago Press, Chicago

Muller MN, Wrangham RW (2004) Dominance, aggression and testosterone in wild chimpanzees: a test of the 'challenge hypothesis. 
Anim Behav 67:113-123. https://doi.org/10.1016/j.anbehav.2003. 03.013

Muller MN, Emery Thompson M, Wrangham RW (2006) Male chimpanzees prefer mating with old females. Curr Biol 16:2234-2238

Muller MN, Kahlenberg SM, Thompson E, Wrangham RW (2007) Male coercion and the costs of promiscuous mating for female chimpanzees. Proc R Soc Lond B 274:1009-1014. https://doi.org/10.1098/ rspb.2006.0206

Murray CM, Eberly LE, Pusey AE (2006) Foraging strategies as a function of season and rank among wild female chimpanzees (Pan troglodytes). Behav Ecol 17:1020-1028

N'Guessan AK, Ortmann S, Boesch C (2009) Daily energy balance and protein gain among Pan troglodytes verus in the Taï National Park, Côte d'Ivoire. Int J Primatol 30:481-496. https://doi.org/10.1007/ s10764-009-9354-1

Neumann C, Duboscq J, Dubuc C, Ginting A, Irwan AM, Agil M, Widdig A, Engelhardt A (2011) Assessing dominance hierarchies: validation and advantages of progressive evaluation with Elo-rating. Anim Behav 82:911-921

Nurmi NO, Hohmann G, Goldstone LG, Deschner T, Schülke O (2018) The "tolerant chimpanzee"- towards the costs and benefits of sociality in female bonobos. Behav Ecol 29:1325-1339

Nurnberg P, Berard JD, Epplen JT, Schmidtke J (1994) Alternative reproductive tactics and reproductive success in male rhesus macaques. Behaviour 129:177-201

Parker GA (1979) Sexual selection and sexual conflict. In: Blum MS, Blum NA (eds) Sexual selection and reproductive competition in insects. Academic Press, New York, pp 123-166

Pontzer H, Wrangham RW (2004) Climbing and the daily energy cost of locomotion in wild chimpanzees: implications for hominoid locomotor evolution. J Hum Evol 46:315-333. https://doi.org/10.1016/j. jhevol.2003.12.006

Pontzer H, Raichlen DA, Shumaker RW, Ocobock C, Wich SA (2010) Metabolic adaptation for low energy throughput in orangutans. Proc Natl Acad Sci U S A 107:14048-14052

Pontzer H, Raichlen DA, Rodman PS (2014) Bipedal and quadrupedal locomotion in chimpanzees. J Hum Evol 66:64-82

Pontzer H, Brown MH, Raichlen DA, Dunsworth H, Hare B, Walker K, Luke A, Dugas LR, Durazo-Arvizu R, Schoeller D (2016) Metabolic acceleration and the evolution of human brain size and life history. Nature 533:390-392

Pusey AE (1990) Behavioural changes at adolescence in chimpanzees. Behaviour 115:203-246

Pusey A, Williams J, Goodall J (1997) The influence of dominance rank on the reproductive success of female chimpanzees. Science 277 : $828-831$

Pusey AE, Oehlert GW, Williams JM, Goodall J (2005) Influence of ecological and social factors on body mass of wild chimpanzees. Int J Primatol 26:3-31

R Development Core Team (2016) R foundation for statistical computing. R: a language and environment for statistical computing, Vienna, Austria, http://www.R-project.org

Rubenstein AH, Clark JL, Melani F, Steiner DF (1969) Secretion of proinsulin C-peptide by pancreatic $\beta$ cells and its circulation in blood. Nature 224:697-699. https://doi.org/10.1038/224697a0

Saito C (1996) Dominance and feeding success in female Japanese macaques, Macaca fuscata: effects of food patch size and inter-patch distance. Anim Behav 51:967-980. https://doi.org/10.1006/anbe. 1996.0100

Schmidt-Nielsen K (1997) Animal physiology: adaptation and environment. Cambridge University Press, Cambridge

Schubert M, Schradin C, Rödel HG, Pillay N, Ribble DO (2009) Male mate guarding in a socially monogamous mammal, the round-eared sengi: on costs and trade-offs. Behav Ecol Sociobiol 64:257-264

Setchell JM (2008) Alternative reproductive tactics in primates. Cambridge University Press, Cambridge
Smith RJ, Jungers WL (1997) Body mass in comparative primatology. J Hum Evol 32:523-559

Sobolewski ME, Brown JL, Mitani JC (2013) Female parity, male aggression, and the challenge hypothesis in wild chimpanzees. Primates 54:81-88

Stanford CB, Wallis J, Mpongo E, Goodall J (1994) Hunting decisions in wild chimpanzees. Behaviour 131:1-18. https://doi.org/10.1163/ $156853994 X 00181$

Steenbeek R, Sterck EH (1997) Female dominance relationships and food competition in the sympatric Thomas langur and long-tailed macaque. Behaviour 134:749-774

Steiner DF, Oyer PE (1967) The biosynthesis of insulin and a probable precursor of insulin by a human islet cell adenoma. Proc Natl Acad Sci U S A 57:473-480

Sterck EHM, Watts DP, van Schaik CP (1997) The evolution of female social relationships in nonhuman primates. Behav Ecol Sociobiol 41:291-309. https://doi.org/10.1007/s002650050390

Stubbs RJ, Tolkamp BJ (2006) Control of energy balance in relation to energy intake and energy expenditure in animals and man: an ecological perspective. Brit J Nutr 95:657-676. https://doi.org/10.1079/ BJN20041361

Stumpf RM, Boesch C (2005) Does promiscuous mating preclude female choice? Female sexual strategies in chimpanzees (Pan troglodytes verus) of the Taï National Park, Côte d'Ivoire. Behav Ecol Sociobiol 57:511-524

Surbeck M, Deschner T, Behringer V, Hohmann G (2015) Urinary Cpeptide levels in male bonobos (Pan paniscus) are related to party size and rank but not to mate competition. Horm Behav 71:22-30. https://doi.org/10.1016/j.yhbeh.2015.03.007

Taylor CR, Heglund NC, McMahon TA, Looney TR (1980) Energetic cost of generating muscular force during running: a comparison of large and small animals. J Exp Biol 86:9-18

Tobias JA, Montgomerie R, Lyon BE (2012) The evolution of female ornaments and weaponry: social selection, sexual selection and ecological competition. Phil Trans R Soc B 367:2274-2293

Trivers R (1972) Parental investment and sexual selection. In: Campbell BG (ed) Sexual selection and the descent of man, 1871-1971. Aldine Gruyter, New York, pp 136-179

Tsuji Y, Kazahari N, Kitahara M, Takatsuki S (2008) A more detailed seasonal division of the energy balance and the protein balance of Japanese macaques (Macaca fuscata) on Kinkazan Island, northern Japan. Primates 49:157-160. https://doi.org/10.1007/s10329-0070070-1

van Schaik CP (1989) The ecology of social relationships among female primates. In: Standen V, Foley RA (eds) Comparative socioecology: the behavioural ecology of humans and other mammals. Blackwell Scientific, Oxford, pp 195-218

van Schaik CP (1996) Social evolution in primates: the role of ecological factors and male behaviour. P Brit Acad 88:9-31

von Holst D, Hutzelmeyer H, Kaetzke P, Khaschei V, Rödel HG, Schrutka H (2002) Social rank, fecundity and lifetime reproductive success in wild European rabbits (Oryctolagus cuniculus). Behav Ecol Sociobiol 51:245-254

Watts DP, Pusey AE (2002) Behavior of juvenile and adolescent great apes. In: Pereira ME, Fairbanks LA (eds) Juvenile primates: life history, development, and behavior. Oxford University Press, New York, pp 148-167

Watts HE, Tanner JB, Lundrigan BL, Holekamp KE (2009) Postweaning maternal effects and the evolution of female dominance in the spotted hyena. Proc R Soc Lond B 276:2291-2298

Wessling EG, Deschner T, Mundry R, Pruetz JD, Wittig RM, Kühl HS (2018a) Seasonal variation in physiology challenges the notion of chimpanzees (Pan troglodytes verus) as a forest-adapted species. Front Ecol Evol 6:60. https://doi.org/10.3389/fevo.2018.00060

Wessling EG, Kühl HS, Mundry R, Deschner T, Pruetz JD (2018b) The costs of living at the edge: seasonal stress in wild savanna-dwelling 
chimpanzees. J Hum Evol 121:1-11. https://doi.org/10.1016/j. jhevol.2018.03.001

Whitten PL (1983) Diet and dominance among female vervet monkeys (Cercopithecus aethiops). Am J Primatol 5:139-159

Wittig RM (2018) Taï chimpanzees. In: Vonk J, Shackelford T (eds) Encyclopedia of animal cognition and behavior. Springer International Publishing, New York, NY, pp 1-7

Wittig RM, Boesch C (2003) Food competition and linear dominance hierarchy among female chimpanzees of the Tai National Park. Int J Primatol 24:847-867

Wrangham RW (1980) An ecological model of female-bonded primate groups. Behaviour 75:262-300

Wrangham RW, Chapman CA, Clark-Arcadi AP, Isabirye-Basuta G (1996) Social ecology of Kanyawara chimpanzees: implications for understanding the costs of great ape groups. In: McGrew WC,
Marchant LF, Nishida T (eds) Great ape societies. Cambridge University Press, Cambridge, pp 45-57

Wroblewski EE, Murray CM, Keele BF, Schumacher-Stankey JC, Hahn BH, Pusey AE (2009) Male dominance rank and reproductive success in chimpanzees, Pan troglodytes schweinfurthii. Anim Behav $77: 873-885$

Zhang Z-Q, Wang D-H (2007) Seasonal changes in thermogenesis and body mass in wild Mongolian gerbils (Meriones unguiculatus). Comp Biochem Physiol A 148:346-353. https://doi.org/10.1016/j. cbpa.2007.05.012

Publisher's note Springer Nature remains neutral with regard to jurisdictional claims in published maps and institutional affiliations. 